\title{
Saúde, meio ambiente e território: uma discussão necessária na formação em saúde
}

\author{
Health, environment and territory: \\ a necessary discussion in health training
}

Cinoélia Leal de Souza ${ }^{1}$

Cristina Setenta Andrade ${ }^{2}$

${ }^{1}$ Programa de PósGraduação em Desenvolvimento Regional e Meio Ambiente, Universidade Estadual de Santa Cruz. Rodovia IhéusItabuna Km 16 Pavilhão Jorge Amado/ $1^{\circ}$ andar/sal 3105, Salobrinho. 45.662000 Ilhéus BA Brasil. cinoelia5@hotmail.com ${ }^{2}$ Universidade Estadual de Santa Cruz.

\begin{abstract}
Environmental degradation has been affecting ecosystems and causing the imbalance of various life forms that comprise natural diversity, and consequently produce risks and hazards to public health. Therefore, an attempt was made to examine interdisciplinary health and environmental health in public undergraduate institutions of higher education involving the application of the concept of territory. It adopted qualitative research with a descriptive and exploratory approach to undergraduate courses in health of the seventeen undergraduate programs in health in the four state universities of the State of Bahia. It was detected that despite curriculum changes in undergraduate courses in health over the past few years, the model of professional training has focused on technical and non-preventive practices, which highlights a gap in the relationship between health/environment and the protection of life. This causes the undergraduate courses in health to minimize the association between diseases, health and environmental issues, taking into account that such issues should be addressed as a cross-sectional theme in undergraduate health, emphasizing the need for more discussion and better incorporation of environmental issues in the healthcare field.
\end{abstract}

Key words Environment and public health, Environmental education, Environmental health, Environment, Curriculum
Resumo A degradação ambiental vem afetando os ecossistemas e provocando o desequilíbrio de várias formas de vida que integram a diversidade natural e, consequentemente, produzindo riscos e agravos à saúde coletiva. Diante disso, buscouse analisar a interdisciplinaridade entre Saúde e Meio Ambiente, na graduação em saúde de instituições públicas de ensino superior frente à aplicação do conceito de território, e pesquisa qualitativa com abordagem descritiva e exploratória. Os dados foram coletados nos programas e ementas de disciplinas de dezessete cursos de graduação na área de Saúde das quatro universidades estaduais da Bahia. Percebeu-se que, apesar das mudanças curriculares pelas quais os cursos de graduação em saúde vêm passando ao longo dos anos, o modelo de formação profissional apresenta foco em técnicas e práticas não preventivas, o que evidencia um distanciamento na relação Saúde/Ambiente e na proteção da vida. Isto faz com que os cursos de graduação em Saúde minimizem associações entre doenças/saúde e questões ambientais, levandose em conta que tais questões devem ser tratadas como tema transversal na graduação em Saúde, sinalizando claramente a necessidade de mais discussões e melhor incorporação da temática ambiental no campo da saúde.

Palavras-chave Meio ambiente e saúde pública, Educação ambiental, Saúde ambiental, Meio ambiente, Currículo 


\section{Introdução}

O Brasil avançou ao longo dos anos, com grandes conquistas da sociedade, sobretudo, no setor Saúde, com a criação do SUS, mas ainda enfrenta problemas básicos de estruturação, efetividade e acesso a serviços e equipamentos públicos básicos, como educação, infraestrutura, saneamento básico e saúde.

Tais problemas refletem diretamente no quadro de Saúde da população, que apresenta particularidades na transição epidemiológica vistas em países em desenvolvimento, como a junção de doenças não transmissíveis com doenças infectocontagiosas já existentes, resultando em novos e velhos problemas de saúde pública, na qual se soma a agenda tradicional dos problemas de saúde enfrentados pela população ao longo de décadas, com as novas doenças e agravos decorrentes da mudança de hábitos da população e agregação de novos estilos de vida, alimentação e moradia. O Brasil é considerado um retrato da acumulação epidemiológica, em que mais de $50 \%$ da mortalidade atualmente deve-se a doenças do aparelho circulatório e a causas externas. No entanto, permanecem as doenças infecciosas e desnutrição, ressurgem a dengue e a cólera e crescem os casos de AIDS ${ }^{1}$.

Nota-se também que a urbanização tem sido um fator determinante para a mudança do perfil epidemiológico e da situação de Saúde, especialmente nas grandes cidades, em que as condições de vida vêm se deteriorando, seja pelo resultado direto da poluição e/ou ocupação pela industrialização, ou pela pressão demográfica sobre o Meio Ambiente, ou ainda pelas grandes desigualdades sociais, ampliadas em meio aos dois processos citados.

As cidades vêm crescendo vertiginosamente sem o devido acompanhamento de infraestrutura básica, o que vem gerando ambientes insalubres, exclusão social e carência de sentimento de pertencimento desses territórios de vivência para enfrentamento da questão ambiental. Questão essa fundamental aos indivíduos, famílias e coletividade que, sensibilizados, capacitados e fortalecidos, poderão obter condições para identificar, conhecer, analisar e avaliar os motivos de ocorrência dos problemas que afetam a saúde. $\mathrm{O}$ sentido de pertencer nos territórios em que vivem, ainda pode contribuir para se tomar consciência dessa realidade e participar das decisões para modificá-la, a partir da concepção de participação social como uma ferramenta do processo de Educação Ambiental².
Aqui se resgata a educação em saúde, a Educação Ambiental e a mobilização social como processos permanentes de transformação social, pois contribuem para o exercício democrático do controle social em ações de saneamento do meio e plantação de árvores em jardins ${ }^{2}$, e na implicação de profissionais e usuários na produção do cuidado em saúde para proteção da vida.

A industrialização e a valorização do consumo geram grandes demandas de produção, com o descarte feito cada vez mais rápido. E são inúmeros os produtos, principalmente produtos eletrônicos, que ficam obsoletos em um período de tempo mais curto, gerando um ciclo de produção mais rápido e menos compromissado com os danos produzidos, como a contaminação do solo, da água, a maior produção de resíduos nocivos à saúde, o que implica em maior demanda por serviços de Saúde, saneamento, infraestrutura e também por educação.

Tem-se de um lado o crescimento de grandes empresas e da produção de bens de consumo, e, do outro, o crescimento da desigualdade social, em que as populações pobres vão sendo pressionadas para as periferias, caracterizadas pela ausência de condições básicas de infraestrutura urbana, com padrões indesejáveis de cidadania e de proteção da vida ${ }^{1}$.

Nessa ótica, é possível identificar o quão próximos estão os desafios para o desenvolvimento sustentável em países em desenvolvimento como o Brasil, com a situação de vida das pessoas nos territórios em que vivem e/ou trabalham, e que enfrentam no seu cotidiano as dificuldades impostas pela desigualdade social e os danos oriundos de um desenvolvimento focado estritamente na produção.

No setor Saúde, a formação de profissionais é uma das questões mais discutidas no contexto da Saúde Pública, com uma abrangência, que é um campo de conhecimento que envolve uma série de subáreas, e a prática que lhe dá uma rica e importante diversidade. Entretanto, a ênfase relativa dada às diferentes subáreas tem variado ao longo da história, dependendo do momento político e das questões de Saúde mais relevantes, em cada período e local geográfico. Também não se pode esquecer a influência econômica na política de saúde brasileira, que dificulta a consolidação do Sistema Único de Saúde (SUS), para uma melhor qualidade de vida, e reforça a Saúde como valor de consumo para o fortalecimento da indústria farmacêuti$\mathrm{ca}$, de equipamentos e de outros segmentos ${ }^{3}$.

A concepção de território no campo da Saúde ganha maior relevância a partir do processo 
de descentralização da década de 1990, quando responsabiliza o gestor municipal pela Saúde de seus munícipes e direciona a reorganização da atenção básica baseada em espaços geográficos, considerados territórios dinâmicos, pois envolvia equipamentos e relações sociais que estavam sempre em processo.

Tal perspectiva caracteriza uma concepção de território no setor Saúde que delimita uma população, vivendo em tempo e espaço determinados, com necessidades e problemas de saúde com um perfil demográfico, epidemiológico, administrativo, tecnológico, político, social e cultural, que o caracteriza como um território em permanente construção ${ }^{4}$.

A formação de profissionais em Saúde, com práticas disciplinares em territórios da estratégia Saúde da família e/ou serviços hospitalares em ambientes insalubres, que também produzem resíduos contaminados, deverá buscar a capacidade para responder a essas necessidades emergentes e reemergentes, envolvendo a Educação Ambiental na proteção dos recursos naturais, com papel de destaque nesse processo, como fator transversal na formação em Saúde, na aplicação da temática nos currículos acadêmicos.

Nesse sentido, buscou-se analisar como se dá a interdisciplinaridade entre Saúde e Meio Ambiente, na graduação da área de Saúde de instituições públicas de ensino superior do estado da Bahia, frete a aplicação do conceito de território.

\section{Metodologia}

Trata-se de uma pesquisa qualitativa, com abordagem descritiva e exploratória em que a coleta de dados foi iniciada com a solicitação de documentos referentes às matrizes curriculares, programas e ementas de disciplinas aos Colegiados dos Cursos de graduação em Saúde nas quatro universidades, com vistas a identificar a presença/ausência de articulação entre o conhecimento da saúde e a Educação Ambiental. Cada curso de graduação em Saúde tem em média cinco anos de duração, e cada semestre tem uma média de seis disciplinas. Foram identificadas matrizes e aproximadamente 1020 ementas e programas de disciplinas para identificar 60 ementas e programas de disciplinas por curso com aproximação com a temática ambiental.

Documentos 1 - Matrizes dos cursos de graduação em Saúde: Biomedicina, Enfermagem, Farmácia, Fisioterapia, Medicina, Nutrição, Odontologia e Psicologia.
Documentos 2 - Programas dos cursos de graduação em Saúde: Biomedicina, Enfermagem, Farmácia, Fisioterapia, Medicina, Nutrição, Odontologia e Psicologia.

Documentos 3 - Ementas das disciplinas (saúde/ambiente) dos cursos de graduação: Biomedicina, Enfermagem, Farmácia, Fisioterapia, Medicina, Nutrição, Odontologia e Psicologia.

O tratamento dos dados da pesquisa foi realizado a partir da técnica de análise do conteúdo, em uma aproximação da perspectiva crítico-analítico, em que se buscou desvelar núcleos do sentido por procedimentos sistemáticos que objetivaram a descrição dos conteúdos das fontes de dados secundários, que permitiram a inferência de conhecimentos relativos à Educação Ambiental. O tratamento dos dados foi dividido em três fases: ordenação dos dados; classificação dos dados e análise propriamente dita ${ }^{5,6}$.

Na primeira etapa de ordenação dos dados, o material empírico coletado (documentos e transcrições das entrevistas) foi organizado após uma leitura "exaustiva" (minuciosa) das unidades de análise, identificadas como as matrizes curriculares e ementas dos cursos de graduação da área de saúde, que permitiu a aproximação das primeiras impressões sobre os dados.

A etapa de classificação dos dados agregou e enumerou os dados que representassem os conteúdos e codificassem os núcleos do sentido das matrizes curriculares e disciplinas por tipo de curso de graduação que apresentavam a temática ambiental. E, a partir de então, buscou-se palavras nas unidades de análises dos programas e ementas de disciplinas, que constituíram os núcleos de sentido ${ }^{6}$, tais como: Educação Ambiental, Meio Ambiente, Saúde Ambiental, Saúde e Meio Ambiente, desenvolvimento sustentável, ecologia, ecológica, ecodesenvolvimento, territorialização, território, e demais palavras julgadas relevantes para codificar os núcleos dos sentidos.

A síntese vertical nomeada no Quadro 1 são referentes a um conjunto de ideias que foram identificadas nos programas de disciplinas como palavras chaves, em consonância com a Educação Ambiental. Após identificados nesses documentos as correlações sobre cada núcleo de sentido, conseguiu-se obter uma compreensão geral a partir do entendimento de cada documento sobre o que cada núcleo representa. Já a síntese horizontal nos permitiu a compreensão sobre todos os núcleos de sentidos na perspectiva de todos os documentos.

A análise de conteúdo supõe uma desagregação do material em unidades de sentido, tendo 
Quadro 1. Síntese dos programas das disciplinas de abrangência ambiental nos cursos de graduação em saúde das UEBA, BA mai-jul/2013.

\begin{tabular}{|c|c|c|c|c|c|}
\hline $\begin{array}{ll}\text { Núcleos de Sentido } & \text { UEBA } \\
\end{array}$ & UESC & UEFS & UESB & UNEB & Síntese Horizontal \\
\hline Educação Ambiental; Educação ambiental e saúde & & & & & \\
\hline Saúde Ambiental, Saúde e meio ambiente & & & & & \\
\hline Meio Ambiente & & & & & \\
\hline Desenvolvimento Sustentável & & & & & \\
\hline Ecologia, Ecológica, Ecodesenvolvimento & & & & & \\
\hline Saneamento e meio ambiente & & & & & \\
\hline Epidemiologia e meio ambiente & & & & & \\
\hline Toxicologia & & & & & \\
\hline Microbiologia, Biologia & & & & & \\
\hline Síntese vertical & & & & & \\
\hline
\end{tabular}

Fonte: Dados da pesquisa.

em vista a elaboração posterior das categorias, geradas dos núcleos de sentido. $\mathrm{Na}$ análise final dos dados, os resultados foram submetidos ao método para destacar e relacionar as informações obtidas com a discussão sobre Saúde, Meio Ambiente e Território, na realidade dos cursos de graduação em Saúde.

\section{Resultados}

A interdisciplinaridade é uma questão fundamental, quando se pensa em educar sobre as questões ambientais, o que pode ser evidenciado na Política e na Educação Ambiental, que é um componente essencial e permanente da educação nacional, devendo estar presente, de forma articulada, em todos os níveis e modalidades do processo educativo, em caráter formal e não formal'

Nos dezessete cursos de graduação em Saúde estudados, onze aproximam conteúdos sobre Meio Ambiente, distribuídos em disciplinas de conteúdos gerais do curso, e seis não apresentaram nenhuma relação de conteúdo sobre meio ambiente nos programas das disciplinas e/ou módulos gerais do curso de graduação.
Trata-se de um achado positivo, pois demonstra que a questão referente à interferência do meio ambiente na saúde da sociedade não tem sido focada exclusivamente em disciplinas específicas da matriz curricular dos cursos de graduação em Saúde. Vale ressaltar que, a partir da Constituição de 1988, e posterior implantação do SUS em 1990, a incorporação de um conceito de saúde passou a ser aplicado de forma mais abrangente. Esse conceito passou a ser visto tanto como resultante das condições de vida, acesso aos serviços de Saúde, como também de fatores individuais, que busquem um estilo de vida saudável, além da relação com o Meio Ambiente, que procura romper com abordagem biologicista, própria da formação em saúde, para um olhar voltado para os determinantes sociais de Saúde.

Há uma diferenciação na abordagem ambiental na formação dos profissionais de Saúde, pois se percebe que, os cursos de Psicologia, Odontologia, Nutrição e em um dos cursos de Fisioterapia, foram os que mais se distanciaram da discussão interdisciplinar sobre Saúde e Meio Ambiente, ambos não apresentaram, nos programas e ementas das disciplinas e/ou módulos, nenhum fator que aproximasse essa relação. Tais 
profissões, ao longo da história, vêm atuando para uma clínica individual, restrita, que pouco percebe as necessidades e problemas do coletivo e a importância do Meio Ambiente na proteção da vida (Quadro 2).

Nos cursos de graduação em saúde da UEBA, também existe uma predominância de conteúdos voltados quase que exclusivamente para a relação parasito-hospedeiro-ambiente. Essas disciplinas focam principalmente as doenças infectocontagiosas e direcionam para a prevenção de agravos, deixando muitos aspectos importantes como secundários, a exemplo pode-se citar as áreas de vulnerabilidade, as dificuldades de acesso à saúde devido a entraves ambientais, ou mesmo uma discussão mais profunda sobre território em saúde.

Muitos cursos apresentaram componentes curriculares que se aproximam da discussão interdisciplinar entre saúde e meio ambiente, mesmo não sendo uma disciplina específica sobre o tema ambiental, a exemplo das disciplinas Saúde Coletiva e Epidemiologia. Tais disciplinas e/ ou módulos de Saúde Coletiva se destacam, de forma positiva, pois na sua própria concepção trazem o componente da interdisciplinaridade na identificação dos problemas e necessidades da população e do ambiente, buscando analisar e intervir com conteúdos diversos que se integram no aprendizado.
A concepção de território nas disciplinas/ módulos de Saúde Coletiva é inferida enquanto espaço dinâmico de produção do cuidado em saúde e desenvolvem práticas em áreas de abrangência da estratégia saúde da família.

\section{Discussão}

As mudanças na política de Saúde no país têm direcionado a reorganização da atenção básica que resgata os sujeitos sociais, a dinâmica de interesses, as relações de cidadania e direito, através de uma ação social que atenda as necessidades da população nos territórios onde vivem. Tal perspectiva envolve ações no ambiente com ênfase na promoção da saúde para proteção à vida.

A incorporação das questões do Meio Ambiente nas políticas de saúde, e a integração dos objetivos da Saúde Ambiental são emergentes, principalmente quando se pensa na formação em Saúde com conteúdos sobre Meio Ambiente, distribuídos em disciplinas de conteúdos gerais do curso. O profissional de Saúde deve, como qualquer cidadão, estar munido de conhecimento que direcione suas ações com vistas à efetivação de suas práticas para proteção da vida nos territórios em que atuará e diante das necessidades impostas pela sociedade.

Quadro 2. Relação entre curso de saúde e disciplinas que apresentam conteúdos sobre Meio Ambiente, UEBA, Bahia, 2013.

\begin{tabular}{|l|l|}
\hline \multicolumn{1}{|c|}{ Cursos } & \multicolumn{1}{|c|}{ Disciplinas com conteúdos sobre Meio ambiente } \\
\hline Enfermagem & Biologia, Parasitologia Humana, Farmacobotânica, Saúde Coletiva, Parasitologia \\
\hline Farmácia & Epidemiologia; Qualidade de Águas, Vigilância à Saúde, Microbiologia; Toxicologia \\
\hline Medicina & Módulo Práticas de Integração Ensino, Serviços e Comunidade (PIESC) \\
\hline Medicina & $\begin{array}{l}\text { Módulo Práticas de Integração Ensino, Serviços e Comunidade (PIESC); Módulo Medicina } \\
\text { Social e Clínica }\end{array}$ \\
\hline Nutrição & \\
\hline Psicologia & \\
\hline Odontologia & \\
\hline Biomedicina & Vigilância à Saúde \\
\hline Fisioterapia & Microbiologia e Imunologia \\
\hline Fisioterapia & \\
\hline
\end{tabular}

Fonte: Dados da pesquisa. 
Quando há uma predominância de conteúdos voltados para a relação parasito-hospedeiro-ambiente, direcionados para o cuidado e a prevenção de doenças infectocontagiosas na formação em Saúde, as disciplinas minimizam problemas ambientais em áreas de vulnerabilidade e pouco aprofundam para uma discussão interdisciplinar que envolva território em Saúde, apesar da incorporação da saúde ambiental como área específica da inter-relação entre Saúde e Meio Ambiente, e das discussões de ambientalistas e sanitaristas para responder às novas propostas de Saúde como qualidade de vida, dependente de fatores condicionantes, dentre eles o fator ambiental ${ }^{8}$.

$\mathrm{O}$ crescimento econômico pouco tem minimizado às desigualdades socais e continua a deslocar a população carente para áreas periféricas sem infraestrutura, com carência de equipamentos sociais e com menor proteção ambiental, o que tem gerado histórias de vida e saúde excludentes e diversificadas, que constituem a complexidade do trabalho em Saúde enfrentada pelos profissionais da área.

O distanciamento da discussão interdisciplinar sobre Saúde e Meio Ambiente dos cursos de Psicologia, Odontologia, Nutrição e em um dos cursos de Fisioterapia é preocupante, pois cada vez mais esses profissionais são absorvidos em serviços públicos de Saúde para atuar em territórios com maior complexidade social, que demandam novas relações sociais na identificação de problemas existentes para produção de modos de cuidar singulares.

A produção em massa de bens de consumo, através de grandes empresas e multinacionais, para o consumo exagerado, e em menor escala de micro e pequenas empresas, da agricultura familiar e de muitas outras atividades na produção de resíduos e o gerenciamento de resíduos, é uma constante em todos os setores da sociedade, até mesmo do setor saúde.

Os resíduos gerados pela assistência à saúde, quando gerenciados de forma inadequada, são contaminantes potenciais do solo, da água e do ar e, portanto, exigem tratamento específico para a preservação do meio ambiente. Ressaltando-se que o próprio ambiente de ensino da saúde é um constante produtor de resíduos considerados de elevado risco, uma vez que, além de poder afetar a Saúde das pessoas, podem causar danos ao Meio Ambiente 9 .

A Saúde e o desenvolvimento estão intimamente relacionados, pois tanto um desenvolvimento insuficiente pode conduzir à pobreza, como um desenvolvimento inadequado pode levar a um consumo excessivo, que, associados a uma população mundial em expansão, podem resultar em sérios problemas para a Saúde relacionados ao Meio Ambiente, tanto nos países em desenvolvimento como nos desenvolvidos ${ }^{10}$.

Sabe-se que o conceito de desenvolvimento sustentável motivou, desde o início de seu uso, o envolvimento por parte de segmentos da universidade. Na sequência do Relatório Brundtland, grupos de universidades constituíram-se em signatários de Cartas e Declarações elaboradas em torno dos princípios da sustentabilidade expressos pelo relatório ${ }^{11}$. Neste contexto, a Saúde foi direcionada para discussões dos determinantes sociais de Saúde a partir das necessidades e dos problemas da população.

Formar profissionais capazes de criticar, refletir e propor alternativas e estratégias para solução e minimização de problemas vivenciados pela sociedade, sobretudo na sua própria realidade, não pode estar dissociado de formar cidadãos, e, nesse ponto, a instituição formadora, seja ela escola ou universidade, não pode pecar. Promover uma educação efetiva diante das necessidades sociais, de Saúde, ambientais e culturais é mais do que uma das funções da universidade, perpassa a necessidade e o direito à qualidade de vida que é reafirmada a cada discussão sobre educação.

As questões do desenvolvimento sustentável estão em relação direta com as funções da universidade uma vez que a educação é essencial para suscitar mudanças no comportamento esperado do indivíduo, enquanto que a investigação e a inovação social, científica e tecnológica funcionam como alavancas do desenvolvimento sustentável ${ }^{12}$.

A Conferência das Nações Unidas sobre o Desenvolvimento Sustentável (Rio + 20) em 2012 buscou renovar um compromisso político com o desenvolvimento sustentável, diante do pouco avanço que se teve em questões básicas ainda discutidas na Conferência Rio $92^{13}$. No setor Saúde, a Diretoria Nacional do Centro Brasileiro de Estudos de Saúde (CEBES $)^{14}$ reafirmou que quase não se avançou na abordagem do tema ambiente na saúde.

A década passada deixou evidências de que a pesquisa e o ensino superior contribuem para a erradicação da pobreza, para o desenvolvimento sustentável e para o progresso, atingindo as metas internacionais de desenvolvimento, portanto a pauta da educação mundial deve refletir essas realidades ${ }^{15}$.

Em anos de discussões, os encontros e conferências internacionais intensificaram o alerta 
sobre os impactos das ações humanas no Meio Ambiente e as suas inevitáveis consequências. É notório que, em todos esses movimentos em prol do desenvolvimento sustentável, é reafirmado por países do mundo inteiro que é preciso pensar num desenvolvimento "consciente" e repensar a impregnação de valores consumistas na sociedade contemporânea, revalorizar as diversidades culturais para um desenvolvimento justo.

Dessa forma, o cenário global da saúde, resultante de profundas modificações nas relações sociais, econômicas e ambientais, se expressa em transições epidemiológica, nutricional e demográfica, que exigem esforços dos sistemas de saúde na busca de sinergias entre a saúde e os demais setores de governo e da sociedade ${ }^{16}$.

Não é possível alcançar o tão almejado desenvolvimento sustentável, sem considerar as tantas desigualdades enfrentadas por inúmeras pessoas em tantas partes do mundo. Não pode haver desenvolvimento sustentável sem existir redução da pobreza e promoção de acesso a equipamentos básicos, como: saneamento básico, infraestrutura urbana, acesso à água potável, à alimentação de qualidade, à educação, à Saúde e a tantos outros serviços imprescindíveis à sobrevivência humana digna.

Saúde e doença distribuem-se fundamentalmente conforme o nível de renda e da equidade na sua distribuição, isso condiciona o amplo conjunto de outros componentes desta determinação. Por outro lado, não pode haver desenvolvimento capaz de ser sustentável sem o componente essencial da saúde. Atrás de todo este processo está o modelo de produção e consumo vigente, desigual, excludente e insustentável ${ }^{16}$.

A Conferência Rio+20, precedida pela Conferência Internacional de Saúde Urbana, pela Conferência Mundial sobre Determinantes Sociais da Saúde, em 2011, e pelos Seminários Nacionais de Promoção da Saúde e de Saúde Ambiental, colocou em destaque as relações entre Desenvolvimento Sustentável e Saúde, na perspectiva da promoção da equidade ${ }^{17}$.

Tal perspectiva nos remonta à Reforma Sanitária como um movimento em defesa da vida e a possibilidade de continuidade da vida. Tal como a conhecemos hoje, está ameaçada pelo modo de produção capitalista e pela dilapidação da natureza, juntamente com o agravamento das iniquidades sociais, em meio a uma crise global, sistêmica e contínua do capital, que implicam na insustentabilidade da vida e da própria reprodução do modo de produção e consumo ${ }^{17}$.

A abordagem da relação saúde e meio ambiente sob a ótica da equidade busca alcançar e minimizar as desigualdades sociais e ambientais para promover uma saúde universal, igualitária e equânime, e objetivar uma das diretrizes do Sistema Único de Saúde (SUS). Contudo, as conferências internacionais sobre Meio Ambiente pouco se atém a apontar propostas efetivas para minimizar os efeitos causados pelo desenvolvimento "insustentável” na saúde das pessoas, principalmente para países em desenvolvimento.

A importância destacada nas ações de Saúde com foco na territorialização demonstra claramente a necessidade e urgência de incorporação e/ou ampliação das discussões sobre a temática do território na formação em Saúde, tema de grande relevância para as duas áreas do conhecimento: Saúde e Meio Ambiente. Entretanto, os programas e ementas dos cursos de graduação em Saúde, demonstram pouca atenção com a territorialização na Saúde e quais os aspectos ambientais devem ser levados em consideração no estudo do território na área de Saúde. Em verdade, pouco se discute o ambiente como promotor da saúde que necessita ser preservado para futuras gerações.

Existe uma clara necessidade de criar oportunidades de alcançar o desenvolvimento sustentável mediante o crescimento econômico, o desenvolvimento social e a proteção do meio ambiente. É notório, que para alcançar o desenvolvimento sustentável é preciso também controlar os níveis de doenças debilitantes transmissíveis ou não transmissíveis, para que a sociedade possa gozar de um estado de bem-estar físico, social e mental.

As definições de território em Saúde contribuem consideravelmente para uma ampliação da visão sobre intersetorialidade entre Saúde e Meio Ambiente, e essa contribuição se deve em muitos aspectos aos estudos realizados por Milton Santos, sobre espaços geográficos ${ }^{18}$.

Para mudança das práticas na construção social da saúde, a vigilância da saúde pode ser apontada como um caminho para a resolução dos problemas de saúde, uma vez que incorpora a proposta de Lalonde nas dimensões da biologia humana, do ambiente, dos estilos de vida e da organização dos serviços de saúde, que são necessidades sociais e de saúde que envolve riscos e controle de riscos, danos e dos condicionantes e determinantes ${ }^{19}$.

Cabe então redirecionar equipamentos novos e infraestrutura para os serviços de saúde e territórios de produção da saúde, com vistas a uma responsabilização também ambiental para melhorar a qualidade e proteção da vida como mais um desafio para o SUS. 
Acrescenta-se que novas concepções de saúde articulam com as condições de vida, e a própria evolução da ciência no campo da genética e da imunologia contribuíram para o reconhecimento da Saúde enquanto equilíbrio do homem com o ambiente, que sofre influência dos fatores humanos, condições ecológicas e estruturas sociais. Ressalta-se a importância ambiental na integração entre as ações curativa e preventiva, e ganha força a perspectiva da promoção da Saúde que incorpora um ecossistema estável e a conservação de recursos e a justiça social como fundamental para Saúde. Aliado a essas questões, a epidemiologia social aponta que a Saúde e as condições de vida são influenciadas pela dimensão biológica, ecológica e por fatores econômicos. Trata-se de uma concepção positiva no conceito de Saúde, resultante de um processo de produção social que indica qualidade de vida pelo modo de viver a vida das pessoas e pelo acesso a bens e serviços econômicos e sociais ${ }^{1}$.

$\mathrm{O}$ que se considera necessidades sociais em territórios no setor Saúde envolve riscos e controle de riscos, danos que perpassam pelos condicionantes e determinantes. Práticas de intervenção que envolvem o ambiente são referidas a partir dos problemas identificados e demandados de cunho coletivo, como restrição ao uso de cigarros em ambientes públicos, fluoretação da água e o controle sanitário dos alimentos, pouco envolvem a preservação ambiental e ambientes saudáveis. Importante ressaltar a intersetorialidade para intervenção na vigilância da saúde presentes no território-processo com múltiplos olhares na busca de solução dos problemas para proteção da vida ${ }^{1,9}$.

A estratégia Saúde da família, na reorganização da atenção básica para produção do cuidado em áreas de abrangência definidas, consideradas territórios, potencializa uma maior responsabilização para equipe de Saúde, e a presença de agentes comunitários em micro-áreas no monitoramento e prevenção de riscos e agravos e promoção da Saúde. Esses territórios são também cenários de prática na formação de profissionais de Saúde onde identificam-se micro-áreas de riscos para produção do cuidado a partir do perfil epidemiológico, e os equipamentos sociais existentes para caracterizar vulnerabilidade social, física e biológica. Vistos de forma interdisciplinar para enfrentamento de problemas contribuem na construção de novos modos de viver e de trabalhar.

Essa perspectiva deverá ser construída a partir do entendimento oferecido por Milton Santos às categorias de análise do espaço, que emergem como fundamentais, e dentro delas o lugar oferece grande potência para discussão dos determinantes sociais da Saúde. Coaduna com a obra de Milton Santos, nas pesquisas em Saúde Pública para renovação do pensamento geográfico de uma visão de espaço meramente físico, na medida em que vai possibilitar à Epidemiologia pensar essa categoria enquanto relação social e, assim, permitir pensar a doença enquanto processo de mudança da estrutura espacial, e não apenas descrevendo-a.

A reflexão sobre o pensamento de Milton Santos e a saúde pública brasileira se faz, obviamente, pela influência que a vasta produção teórica desse autor legou para a ciência em geral e para a saúde pública em particular. Não que Milton Santos tivesse dedicado parte de sua vida em estudos sobre Geografia da Saúde, mas certamente a preocupação desse autor com o objeto da ciência geográfica acabou por proporcionar uma revisão epistemológica do conceito de espaço e território e, dessa forma, ser capaz de influenciar as demais ciências, como a Economia, a Sociologia e a Epidemiologia ${ }^{20}$.

Também resgata a importância do estudo do espaço para a análise das necessidades e das desigualdades sociais na Saúde, e o atual momento vivenciado pela sociedade mundial de reflexão e ações sobre as práticas humanas agressivas aos recursos naturais. Torna-se um importante momento na formação, para compreender, entender e analisar os aspectos possíveis da Saúde no território. Problematizar os cenários de prática nos permite aproximações sucessivas, tanto para a compreensão, como para a ação na realidade de cada local ${ }^{21}$.

\section{Considerações finais}

A análise interdisciplinar entre Saúde e Meio Ambiente, na graduação da área de Saúde frente a aplicação do conceito de território, permite inferir a importância e a necessidade de continuidade da discussão sobre Meio Ambiente e Saúde nos currículos acadêmicos, e que a presença de uma única disciplina dá a sensação de cumprimento de uma obrigação prevista em lei e não devida a importância dessa discussão no campo da Saúde. Mesmo com a comprovada relevância e comprovada necessidade de inserir na formação em Saúde a discussão e a reflexão sobre o Meio Ambiente pouco é observado nos cursos de graduação das UEBA, sobre a educação ambiental no currículo de graduação em Saúde.

A incorporação das questões do Meio Ambiente nas políticas de Saúde, e a integração dos 
objetivos da saúde ambiental são emergentes, principalmente quando se pensa na formação em Saúde, pois se trata de profissionais que vão cuidar para preservação e proteção da vida, com conhecimento que direcione suas ações com vistas à efetivação de suas práticas diante das necessidades impostas pela sociedade.

Identificar as potencialidades e dificuldades de um determinado território, numa ótica estrutural, física e cultural, e, a partir dessa análise e observação compreender as barreiras impostas pela dinâmica do território, é fundamental no enfrentamento de problemas e necessidades.

As vivências em territórios na Estratégia de Saúde da Família permitem práticas interdisciplinares na relação Saúde e Ambiente, pois se referem a um importante período na graduação em Saúde, para discussão de conteúdos que envolvam a relação Meio Ambiente-Território-Saúde e proporcionem práticas de promoção da Saúde mais efetivas e direcionadas para a realidade e necessidade de cada território.

Muitos cursos estudados apresentaram componentes curriculares que possuem a discussão interdisciplinar entre Saúde e Meio Ambiente, mesmo não sendo uma disciplina específica sobre o tema ambiental, como Saúde Coletiva e Epidemiologia. Todavia, ao analisar essa relação, nota-se que as disciplinas e/ou módulos que se destacam nesse sentido, são majoritariamente as disciplinas de Saúde Coletiva, o que é um fator positivo, pois coadunam com questões socioambientais que afligem as comunidades. A abordagem em saúde coletiva traz o componente da interdisciplinaridade, a partir dos problemas e necessidades da população e do ambiente para buscar-se analisar e intervir com conteúdos diversos que se integram no aprendizado.

As dificuldades em adotar práticas de proteção ambiental, torna a educação uma ferramenta imprescindível para a sensibilização das pessoas.
Dessa forma, a universidade desponta como território pulsante de movimentos de mudança importante para aplicação desses preceitos pelo acumulo de saberes e produções.

Nesse sentido, a efetividade das ações de promoção da Saúde para proteção da vida está condicionada pela potencialidade das ações humanas no território, e as consequências dessas ações, que podem impactar positivamente ou negativamente na saúde e no ambiente. Apesar de abordar em diferentes contextos a importância da ação do profissional de Saúde nos diferentes territórios, que é uma questão chave tanto no campo de conhecimento da Saúde quanto do Meio Ambiente, os programas e ementas curriculares pouco abordam a praticidade dessa relação.

Discutir as relações existentes na natureza e suas implicações nos diferentes tipos de vida na terra com futuros profissionais de Saúde é imprescindível, para a efetividade das políticas voltadas para o Meio Ambiente, como também nas práticas de Saúde, visto que os estabelecimentos de Saúde são grandes produtores de resíduos e consumidores de energia, além de cuidar de populações que vivenciam em territórios produtores de Saúde e doença.

Deve-se considerar em próximos estudos também a necessidade de escutar os anseios e as opiniões de professores e estudantes sobre a inserção da temática ambiental no cotidiano da formação para a Saúde.

Fica patente que as dificuldades em adotar práticas de proteção ambiental, tornam a educação um dispositivo para implementar alternativas diversificadas de mudanças em instituições que exercem um papel fundamental na proposição e execução de políticas na educação para Saúde, destacando aqui a Universidade, e que esse é um dos desafios a serem rompidos frente a atual dinâmica interdisciplinar do processo de educação, ambiente e saúde.

\section{Colaboradores}

CL Souza e CS Andrade participaram igualmente de todas as etapas de elaboração do artigo. 


\section{Referências}

1. Mendes EV. As redes de atenção à saúde. Brasília: Organização Pan-Americana da Saúde; 2011.

2. Moises M, Kligerman DC, Cohen SC, Monteiro SCF. A política federal de saneamento básico e as iniciativas de participação, mobilização, controle social, educação em saúde e ambiental nos programas governamentais de saneamento. Cien Saude Colet 2010; 15(5):25812591.

3. Ribeiro H. Saúde Pública e meio ambiente: evolução do conhecimento e da prática, alguns aspectos éticos. Saude soc 2004; 13(1):70-80.

4. Mendes EV. Distritos sanitários: processo social de mudanças nas práticas sanitárias para Sistema Único de Saúde. São Paulo, Rio de Janeiro: Editora Hucitec, Abrasco; 1993.

5. Minayo MCS. O desafio do conhecimento: pesquisa qualitativa em saúde. 10a ed. São Paulo: Hucitec; 2007.

6. Bardin L. Análise de Conteúdo. Lisboa: Edições 70; 1977.

7. Brasil. Presidência da República. Casa Civil. Subchefia para Assuntos Jurídicos. Lei № 9.795, de 27 de abril de 1999. Dispõe sobre a Educação Ambiental, institui a Política Nacional de Educação Ambiental e dá outras providências. Diário Oficial da União 1999; 28 abr.

8. Minayo MCS. Saúde e ambiente: uma relação necessária. In: Campos GWS, organizador. Tratado de Saúde Coletiva. São Paulo: Hucitec; 2007. p. 81-109.

9. Muller AM, Silveira D DS, Nara EOB, Kipper LM, Moraes JAR. Um olhar exploratório sobre os resíduos de serviços de saúde para os cursos da área da saúde numa universidade comunitária do Sul do Brasil. Revista Eletrônica em Gestão, Educação e Tecnologia Ambiental 2013; 17(17):3327-3335.

10. MMA. Ministério do Meio ambiente. Secretária de Articulação Institucional e Cidadania Ambiental. Resumo do Documento Agenda 21 da Conferência das Nações Unidas sobre Meio ambiente e Desenvolvimento - 1992. [internet] 1992. [acessado 2012 maio 22]. Disponível em: http://www.mma.gov.br/sitio/index.php?ido=conteudo. monta\&idEstrutura $=18$ \&idConteudo $=577$

11. Graham A. Report on Higher Education Sustainability Activities. Cambridge: MTI-USA; 2004.

12. Couto AP, Bryan NAP, organizadores. Los Desafios de la Gestión Universitária hacia el Desarrollo Sostenible. Campinas: Unicamp; 2005. p. 25-48.

13. Organização das Nações Unidas (ONU). El futuro que queremos. Rio de Janeiro: PNUMA; 2012.
14. Centro Brasileiro de Estudos de Saúde (CEBES). Desenvolvimento e Sustentabilidade: desafios da Rio +20 . Saúde em Debate 2012; 36(especial):4-12.

15. Organização das Nações Unidas para a Educação, a Ciência e a Cultura (UNESCO). Conferência Mundial sobre Ensino Superior 2009: As Novas Dinâmicas do Ensino Superior e Pesquisas para a Mudança e o Desenvolvimento Social. Paris: UNESCO; 2009.

16. Brasil. Ministério da Saúde (MS). Saúde e Desenvolvimento Sustentável: Saúde Na Rio + 20. Brasília. 12 de dezembro de 2011. [internet] 2011. [acessado 2013 jun 25]. Disponível em: http://www.sauderio20.fiocruz.br/ attachments/article/65/SaudeRio20documorientadorMS.pdf

17. Gallo E, Setti AFF, Magalhães DP, Machado JMH, Buss DF, Netto FAF, Buss PM. Saúde, Desenvolvimento Sustentável e a Defesa da Vida. Saúde em Debate 2012; 36(especial):13-16.

18. Saquet MA, Silva SS. Milton Santos: concepções de geografia, espaço e território. Geo UERJ 2008; 2(18):24-42.

19. Paim J. Modelos de Atenção e Vigilância da Saúde. In: Rouquayrol MZ, Almeida Filho, organizadores. Epidemiologia \& Saúde. Rio de Janeiro: MEDSI; 2003. p. 567-571.

20. Faria RM, Bortolozzi A. Espaço, Território E Saúde: contribuições de Milton Santos para o tema da geografia da saúde no Brasil. R. RA'EGA 2009; 1(17):31-41.

21. Pekelman R, Santos AA. Território e lugar - espaços da complexidade. [internet] 2009. [acessado 2013 set 15]. Disponível em: http://moodle3.mec.gov.br/ufam/file. php/1/Biblioteca_Geral_do_Curso/texto01_territorio _e_lugar.pdf

Artigo apresentado em 01/07/2014

Aprovado em 11/07/2014

Versão final apresentada em 12/07/2014 